IRA-International Journal of Education \& Multidisciplinary Studies

ISSN 2455-2526; Vol.06, Issue 02 (2017)

Pg. no. 195-208

Institute of Research Advances

https://research-advances.org/index.php/IJEMS

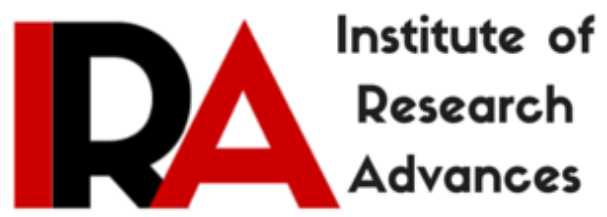

\title{
Analysis of Speech-Sign Semantic Equivalence in Simultaneous Communication in Kenya
}

\section{Adoyo Peter Oracha}

Department of Special Needs Education, Maseno University, P.O Box 333, Maseno

Kenya.

Type of Review: Peer Reviewed.

DOI: http://dx.doi.org/10.21013/jems.v6.n2.p7

\section{How to cite this paper:}

Oracha, A. (2017). Analysis of Speech-Sign Semantic Equivalence in Simultaneous Communication in Kenya. IRA International Journal of Education and Multidisciplinary Studies (ISSN 2455-2526), 6(2), 195-208. doi:http://dx.doi.org/10.21013/jems.v6.n2.p7

(C) Institute of Research Advances

\section{(c)) EY-NC}

This work is licensed under a Creative Commons Attribution-Non Commercial 4.0 International License subject to proper citation to the publication source of the work.

Disclaimer: The scholarly papers as reviewed and published by the Institute of Research Advances (IRA) are the views and opinions of their respective authors and are not the views or opinions of the IRA. The IRA disclaims of any harm or loss caused due to the published content to any party. 


\subsection{Introduction}

Effective communication between teacher and pupil is a requisite factor for educational attainment. For the deaf, ineffective communication is a major problem especially when onset of profound deafness takes places at an early age before language is acquired. At school, the language of classroom communication not only affects the child's development but also influences ability to learn other curriculum contents. Pointing out reasons for failure by deaf children to compete favorably with their hearing peers, Johnson et al (1989) has indicated that the central problem on deaf education is embedded in the lack of an appropriate language of classroom communication.

For a long time education for the deaf was conducted through the oral approach. It was later realized that this oral approach did not avail curriculum content to the deaf learners. In the 1980's Total Communication arose as one of the solutions. According to Adoyo (2004), Total Communication was misunderstood for Simultaneous Communication, a communication system in which speech and sign are produced at the same time (Lane, Hoffmister \& Bahan, 1996). Although SC has been used in Kenya for all these years, it has not produced the predicated large-scale improvement.

In this study, an attempt was made to establish the capacity of SC to enhance understanding and to facilitate information processing. The investigation was carried out through an examination of the extent to which the spoken and signed messages were equivalent in meaning. The research question was: To what extent do teachers of the deaf maintain one-one, sign to-voice ratio during Simultaneous Communication transmission and to what degree is the spoken and signed message equivalent semantically?

\subsection{Methodology}

The investigation took two approaches: The first section attempted to investigate the extent to which teachers maintained a one-to-one, sign-to-voice ration during SC transmission. The second part evaluated simultaneity at semantic level and the attempt was to determine the extent to which the communicated message in the gestural channel was semantically equivalent to the vocal channel conveyed message. Semantic Code (Stahlman and Luckner 1991 was used in the analysis.

\subsection{Respondents}

Sources of the analysed data were three hearing teachers, one male and two females where ages ranged from 38 to 40 years. The teachers were from three large residential schools in Western Kenya. All lived within the school campuses, and interacted with the deaf students during and even after school hours. The official language policy in the school was the use of SC in every aspect of the school communication. The teachers were specially trained in communication skills for the deaf and had SC experience in the classroom for more than five years prior to the study. All were highly rated by their colleagues and the administration in Simultaneous Communication.

\subsection{Design and Procedure}

The teachers and pupils were briefed on their role in the study, analyzing their SC use in the classroom. They were assured of confidentiality. They were asked to teach and communicate with the pupils in the class as they always did, being expected to ask questions and to respond to pupils' questions if there were any. Observations were conducted in quite rooms in the mornings. The first teacher had 12 pupils, 6 boys and 6 girls, where average age was $14.6 \mathrm{yrs}$, average hearing loss, $81.7 \mathrm{~dB}$; the second teacher had 13 pupils, 8 boys and 5 girls, average age $14.9 \mathrm{yrs}$; average hearing loss, $88.5 \mathrm{~dB}$; and the third teacher had 11 pupils, all girls; average age, $15.1 \mathrm{yrs}$; and average hearing loss $80.4 \mathrm{~dB}$.

Using a portable video camera Pal-Sony AVC 3210, each teacher was separately video recorded while teaching using SC for instruction. The principal researcher stood 3 meters behind the pupils and recorded the teacher-pupil interaction. 
The first teacher taught Geography, History and civics (GHC) in Grade 8, the second teacher handled Art in grade 8 and the third teacher taught a computer lesson in grade 9. Evidence from video clips indicated that neither the camera not the presence of the researcher disturbed the teachers and pupils during the presentation. The three clips from the three teachers were then transferred to the bigger tapes for VCR playback and analysis.

\subsection{Coding procedure}

The spoken and signed utterances of each teacher's communication were first studied on video by four coders, the principal researcher, two native deaf signers and one hearing teacher, fluent in SC before they were transcribed. Each recorded SC clip appeared in voice and sign channels transcribed in parallel using Sync WRITTER. This programme notates speech and sign communication without loosing track of the interlinear structures of the events. Voice appeared in lower case while sign glosses were rendered in upper case. The data was first analyzed for sign-to-voice intact ratio and secondly for semantic equivalence. The utterances were coded at two different levels: at morphological level and at the level of semantic equivalence.

\subsubsection{Morphological level}

Each utterance was categorized for morpheme classification for mismatches as shown in table 1

Table 1: Morpheme Mismatches

\begin{tabular}{|l|l|}
\hline CATEGORY & EXAMPLE \\
\hline Where speech and sign are not identical & Saying good while signing BUT \\
\hline Presence of a word in only one channel & Saying keep and not producing the sign KEEP \\
\hline Lack of tense markers & Saying Jumping while signing JUMP \\
\hline Marking plural in only one channel & Saying cows and while signing COW \\
\hline
\end{tabular}

\subsubsection{Semantic equivalence level}

Message was considered semantically equivalent if each channel clearly represented the same prepositional content that is, the same number of semantic codes. Non-equivalence condition was reached when one or more constituentsdiffered between the two channels to the extent that the messages were not identical perhaps because some prepositional content was either missing or differed. Bloom and Lahay (1978) tool, a taxonomy for semantic category wasused for analysis.

\subsection{Data analysis}

The scope of this study was restricted to teachers' communication and not the learners. Subsequently only the teachers' utterances were transcribed and analyzed to establish the extent to which the teachers maintained a one-to-one, sign to voice ration and to establish through semantic intact ratio the extent to which the spoken and the signed massages were equivalent at the level of meaning.

The analysed data consisted of three transcriptions from three teachers taken during the classroom teaching session using SC as a medium of communication. Two native signers and a bilingual hearing teacher did the coding. In transcribing the signed portion of each utterance, the citation form of each sign was given in English gloss and recorded in order of appearance on the transcribed sign line. Each sign and speech was entered with attention to mismatches, omissions and exact representation. Each transcription was analysed separately using SyncWRITER.

The interlinear transcriptions were broken into sentences, resulting in a score-like format. The transcription of speech and sign occurred synchronously while at the same time aligned to the same position. Synch tabs marked the word and sign entries. It was possible to determine synchronism between texts parts, which were automatically maintained by the programme. Four tracks were used for speech 
channel, sign channel, quizzical facial expression (QF) and translation.Hyphened glosses for instance, b$\mathrm{u}-\mathrm{t}$ were used to indicate finger spelt words.

\subsection{Sign-to-Voice ration}

A sign-to-voice ratio guideline (Luetke-Stahlman 1998) tool was used. The tool when used provides information about the amount of what is signed during SC as compared to what is said. A morpheme was used as a unit of measurement. Taking the total number of signed morphemes in the sample and dividing it by the total number of voiced morphemes in the same sample computed the ration as follows:

$\begin{array}{cccc} & \text { A: the teacher has the ball } \\ \text { B:THE } & \text { TEACHER HAS THE BALL }\end{array}$

In the above sentence, lower case, A donated spoken English and upper case B represented signed utterances. As shown in the transcript, there was a one-to-one sign-to-voice correspondence between A and $\mathrm{B}$, which resulted into exact message transfer from voice to sign. Sign-to-voice ration was therefore computed as follows;

$$
\begin{aligned}
& \text { Total number of signed morphemes }=5 \\
& \text { Total number of voiced morphemes }=5
\end{aligned}
$$

$$
\text { S.T.V }=100 \%
$$

If however in a SC conversation the total voiced, morphemes are 150 the total signed morphemes are 130, sign -to-voice ration would computed as follows;

$$
\begin{gathered}
\text { Total signed morphemes }=130 \times 100 \\
\text { Total voiced morphemes }=150 \\
\text { S.T.V }=86 \%
\end{gathered}
$$

This result is the percentage of what is signed as compared to what is said. Luetke-Stahlman (1998) has pointed out that this ratio should generally be above $90 \%$ for adult signers across a variety of context. Using the forgoing formula, the three teacher's scores in the present study were computed. The results for each teacher was analysed under morphological and semantic levels.

\subsection{Results}

\subsubsection{Exact presentation}

The first morphological analysis included an attempt to find out the presence of the morphemes in the two channels ie. Speech and Sign. It examined the representation of the voiced and signed utterances as required by the principles of SC. These were signed utterances that completely synchronized with the spoken utterances that they accompanied. Each transcription was analyzed separately and the table 2 shows a summary of the total number of voiced morphemes against the total signed morphemes for each teacher. The following pseudo names, Ala, Ali and Wala were used.

Table 2

Summary of Total voiced/Total signed morphemes for Ala, Ali and Wala

\begin{tabular}{|l|c|c|c|}
\hline & Ala & Ali & Wala \\
\hline $\begin{array}{l}\text { Total voiced } \\
\text { Morphemes }\end{array}$ & 760 & 870 & 915 \\
\hline $\begin{array}{l}\text { Total signed } \\
\text { morphemes }\end{array}$ & 260 & 353 & 630 \\
\hline
\end{tabular}

These results revealed varied rates at which the three teachers communicated. Although all were timed for a period of 20 minutes each during the presentation, the total number of voiced and signed morphemesfor each teacher differed significantly. This was quite noticeable especially in Ala, who managed 13-signed 
morphemes per minutes and Wala, who was a head with 31 signed morphemes per minutes. Perhaps this is why Akamatsu and Stewart (1998) have pointed out that having to produce communication in two modalities, one that is automatic and the other one that not, creates difficulties in synchronizing the two communication modes. Akamsau and Stewart have argued that during the simultaneous communication process, the rate of speech production on which signing rests in lowered. This seems to have caused the difference. The following calculations show the sign-to-voice ration the three teachers.

Ala

Total signed morphemes $=260 \times 100$

Total voiced morphemes $=76$

S.T.V ration $=34 \%$

This result indicates that only $34 \%$ of the speech utterances were matched with signs leavings $66 \%$ of the spoken information with omissions. Given that only a reasonable percentage of deaf people (typically the post-lingually deafened and those with substantial amounts of residual hearing) may have lipreading skills. And even for those with lipreading skills, there has been a lot of argument that it is not easy to perceive full information through lipreading. Lynas (1994:39) has reported that the information offered by lipreading is generally limited, as many sounds of speech for instance, $/ \mathbf{P} /$ and $/ \mathbf{m} /$ look a like on the lips. She has noted that some sounds are invisible for example, $/ \mathbf{k} /, / \mathbf{g} /$ and $/ \mathbf{n} /$ and in running speech most vowels are very difficult to differentiate. The majority who are prelingually/profoundly deaf rely on the signed signal for information reception. This group is likely to miss a lot of information if they have to rely on a communication mode with omissions of obligatory information.

The second teacher, Ali, uttered 870 voiced morphemes and represented 353 of the morphemes. The signto-voice ratio was therefore computed as follows:

$$
\begin{gathered}
\text { Ali } \\
\frac{\text { Total signed morphemes }=353 \times 100}{\text { Total voiced morphemes }=870} \\
\text { S.T.V ratio }=40 \%
\end{gathered}
$$

Evidently, from this result, Ali's rate of SC transmission is higher than that of Ala's. This difference is clear in the number of voiced and signed morphemes. However the ratio is still low as there is still quite a large number of sign deletions.

\section{Wala}

For Wala, the Sign-To-Voice ratio was computed as follows:

$\underline{\text { Total signed morphemes }=630 \times 100}$

Total voiced morphemes $=915$

S.T.V. Ratio $=69 \%$

Contrary to Ala and Ali's performance, Wala had the highest number of morphemes produced and synchronized. Although his sin-to-voice ratio is still below LuektkeStahlman's requirement of 90\%, some improvement is beginning to emerge, as there was simultaneity in more than $50 \%$ of the presentation.

\subsubsection{Sign deletions}

These were signs that failed to correspond to the spoken utterances. In other words they appeared in the spoken utterance but were missing in the signed channel. For example,

$$
\begin{aligned}
& \text { A The goats are eatinggrass } \\
& \text { B GOAT GRASS }
\end{aligned}
$$

The transcript except above has seven spoken morphemes, however only two were signed. Five morphemes including the plural marker $(\mathrm{S})$, the auxiliary verb are and the main verb eating, which are 
semantically obligatory are missing. The only two signed utterances GOAT and GRASS have failed to convey the original intended spoken message.

Counting of the gaps in the transcriptions revealed that Ala did not sign $66 \%$ of the spoken morphemes during his SC transmission. Ali omitted 60\% and Wala, deleted 31\%. Examples of such omission are shown in Ala 1,2, and 3.

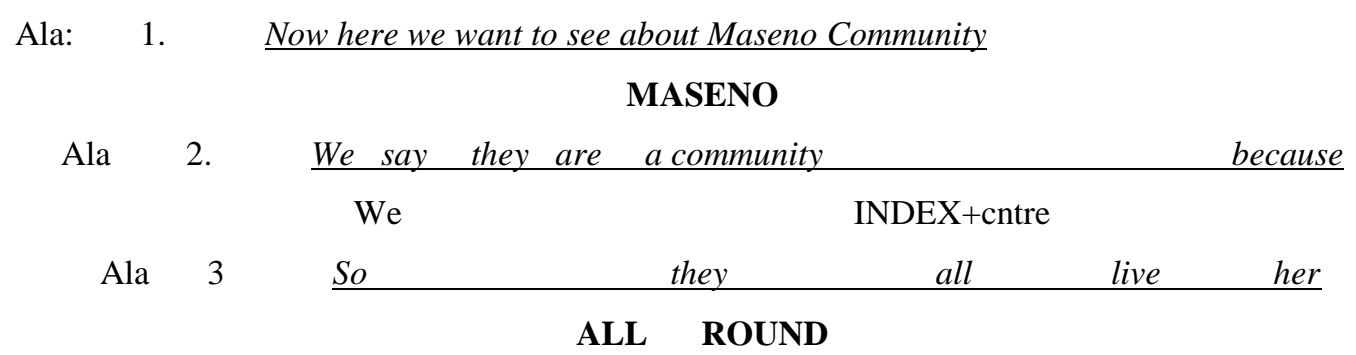

Certainly the proportion of sign deletions to the spoken utterances in terms of number was too high for any intelligibility to occur. Similar omissions were evident in Ali and Wala's transcripts.

$$
\begin{array}{rlr}
\text { Ali; } 4 & \text { Who is not in today? } \\
\text { WHO } & & \text { TODAY }
\end{array}
$$

Even with quizzical face, the forgoing utterance would be difficult to Comprehended.

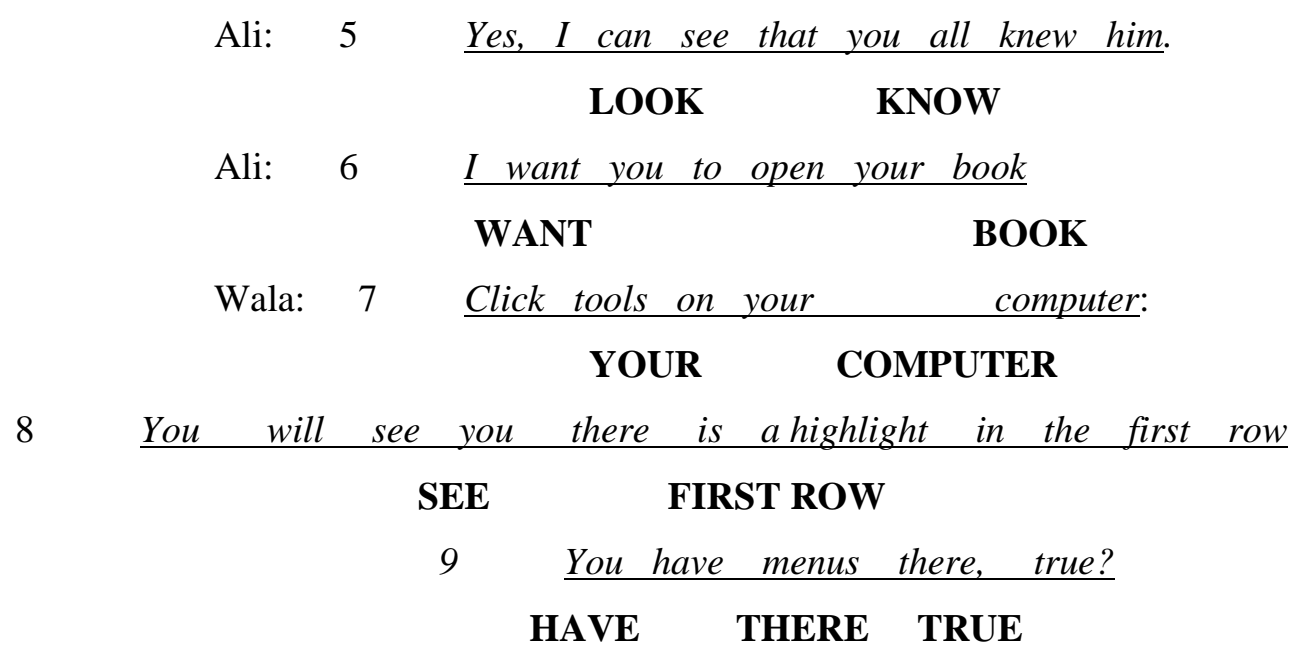

Apart from the foregoing examples of deletions, there were extreme cases in which no single corresponding sign morpheme was matched. Although they were few, they did exist for example
Ala: $\quad 10 \quad$ I want you to tell me people who stay in Maseno
Wala 11 After you have the menus, you look for what

\subsubsection{Mismatches}

For this category, the study analysed spoken and sign morphemes, which were glued together but were not identical and therefore resulted in message contradiction. For example,
A: Do you remember
the day be born?

B: YOU FINISH NOW WAS BORN


In this transcript, the voiced remember is glued with the sign FINISH and voiced "day' mismatched with the sign Now.

The three transcriptions revealed evidence of contradictions though not in large quantities. The number varied from teacher to teacher with Ala recording the highest number, 37 (48\%), Ali had 17 (1.9\%) while Wala had the least, $16(1.7 \%)$.

Three utterances have been chosen from each teacher's transcripts as evidence.

\begin{tabular}{|c|c|c|c|c|c|c|}
\hline & 13 & Now & you & see, & we & have \\
\hline
\end{tabular}

Although the three glosses do not make sense, due to mismatch, deaf pupils may only link the visitor with money by fillings in gaps. This already contradicts the teacher's intended message, which attempted to inform them of visitor's presence.

Ala 14 Now today we want to talk about community

TODAY WRITE

Some sense may be deduced from the signed channel 14, to mean that something must be written today although this is not the originally intended message. Because a number of signed morphemes are omitted, coupled with the mismatch of the spoken morpheme COMMUNITY with signedmorphemeWRITE, it isdifficult to deduce that the original message was essentially about the topic Community. Other examples include:

Ala 15 Last time we talked about family, you remember?

\section{LAST TALK FAMILY THINK}

Ala $16 \quad$ Now, what is the work of the head teacher?
YOU
HEAD TEACHER +QF

With or without the quizzical facial expression the signed utterance in 16 is comprehensible although the massages are no equivalent. The transcript excerpt is an interrogative questions (wh) inquiring on the role of the head teacher in a school set up. Possible answers in this situation would be: he looks after the school, he prepares the school budget, and he helps the students etc. Answers of course would vary from one context to the other. However, due to the deletion of the sign utterance, work with the mismatching of the sign YOU to the voiced now, the question has changed its form to a yes-no type of interrogative utterance. At the same time the message content is not equivalent. Instead of asking the role of the head teacher, by implication, the pupil is being asked to declare whether he is a head teacher or not. This is very confusing and supports Johnson et al (1989) findings which has extensively reported on the loss of meaning due to mismatch of sign and words during simultaneous communication.

Other examples in the category were found in:

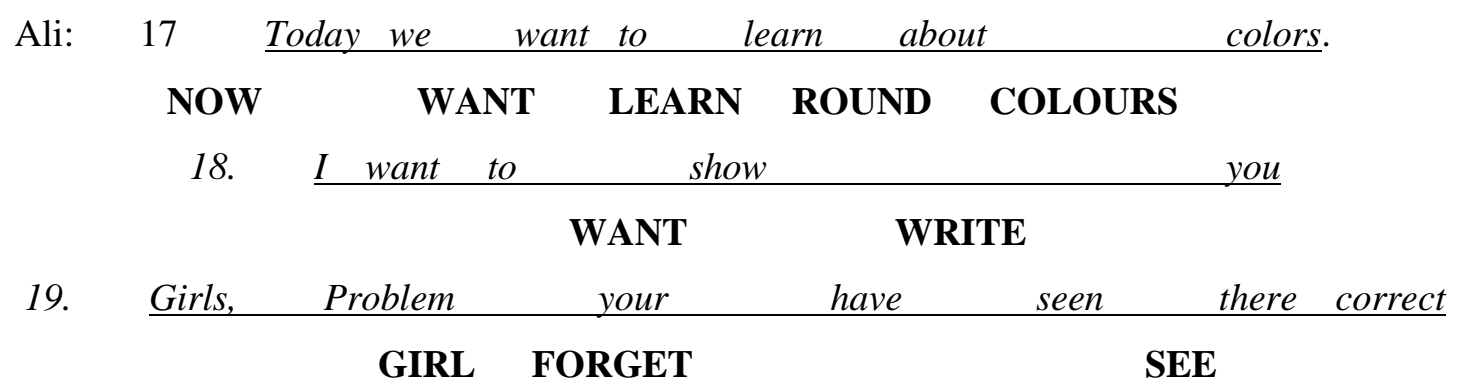


Ali's signed message in 17 is not far from the original information as most of the obligatory morphemes are signed. However, misrepresentation of the spoken morpheme about with ROUND is confusing. And the substitution of show with WRITE in 18 alters the meaning of the intended message. The same phenomenon in 19 in which the voiced problem is matched with signed FORGET interferes with the comprehensibility of the resultant signed message.

Ali's signed message in 17 is not far from original information as most of the obligatory morphemes are signed. However, misrepresentation of the spoken morpheme about with ROUND is confusing. And the substitution of show with WRITE alters the meaning of the intended message. The same phenomenon is in 19 in which the voiced problem is matched with the signed FORGETinterferes with the comprehensibility of the resultant signed message.

Though similar observation were noted in Wals's transcription as explicated in $20-22$, the extent is low:

\begin{tabular}{|c|c|c|c|c|c|c|c|}
\hline \multirow[t]{2}{*}{ Wala } & \multirow[t]{2}{*}{20} & \multicolumn{6}{|c|}{ So do you see insert in the number of columns? } \\
\hline & & SAY & & LOOK & O-F & & COLUMN \\
\hline & 21: & \multicolumn{6}{|c|}{$\underline{\text { NOW this was number one }}$} \\
\hline & \multicolumn{7}{|c|}{ Make } \\
\hline & 22: & $\underline{\text { For }}$ & example & the & first & thing & is boarders, ok \\
\hline
\end{tabular}

\subsubsection{Tense Marker}

Other morphological analysis assessed the inclusion of tense markers, for example, saying, "walking" while signing WALK.

According to the principles of SC, signers are expected to mark tenses example, simple past tense is marked by adding the suffix, -ed, finger spelt after a verb sign, or an addition of suffix ing finger spelt for the present continuous tense use. This did not occur anywhere in the three transcripts. Most of the verbs were signed in their present tense form. For instance:

Ala: 23 Now, we talked about our family

TALK FAMILY

24 It is good but he has changed

LITTLE GOOD BUT CHANGE

25: Infacteven be forget about men

FORGET MEN

Similar occurrences were noted in Ali's utterances;

Ali

26: $\begin{array}{llllll}\text { That one has } & \text { said } & \text { red } & \text { colour } & \text { red } \\ \text { INDEX+cntre } & \text { SAY } & \text { RED } & \text { COLOUR } & \text { RED }\end{array}$

27: $\quad$ These colours are divided into groups 
COLOUR DIVIDE GROUP

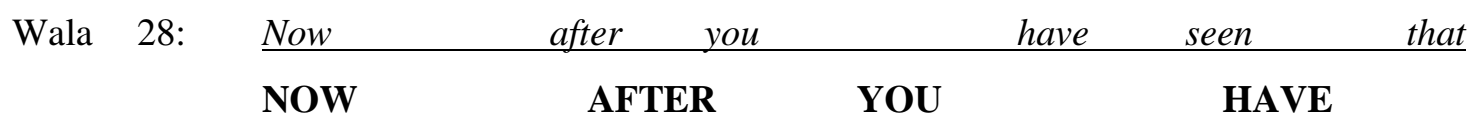

SEE

THAT

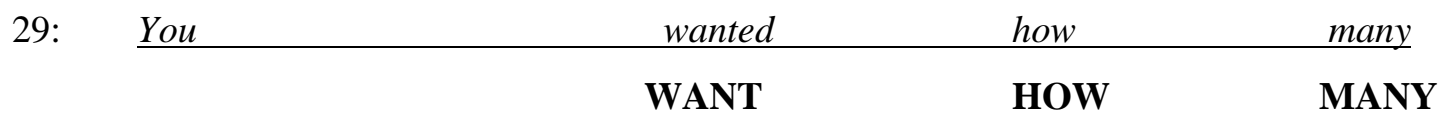

Although lack of tense marking within individual signed verbs were noted in the forgoing. There were cases in which whole utterances were marked in past by means of the use of the sign PAST, which is articulated by waving a flat "B" hand shape with orientation towards the body from the front of back of the shoulder. This is a commonly used strategy in KSL. For example:

$\begin{array}{llllll}\text { Ali 30: } & \text { Last time } & \text { we } & \text { draw } & \text { a man } & \text { standing } \\ & \text { PAST } & & \text { DRAW } & \text { MAN } & \text { STAND }\end{array}$

31: Last time we talked about family
PAST
TALK

A look at Ali-30 reveals that although the individual signed verbs, DRAW and STAND, remain in their root form, the sentences are marked in the past at the beginning of the sentences.

\subsubsection{Number markers}

In KSL numbers are mostly marked by reduplication of the root form of the word for example, CHILD CHILDCHILD denoting children or by the use of adjectival quantifiers such as MANY, FEW etc. For example, CHILD MANY, TEACHERTEN. However, during SC transmission, the sign utterances mark plurals by adding the affix-s at the end of the sentence to mark numbers for regular nouns and fingerspell suffixes in irregular nouns. For example, $\boldsymbol{C H I L D + R - E - N}$

While there were a number of incidences, in which number markings were vital during SC presentations, the teachers did not include them. This makes it difficult to understand number form in SC transmission. For example

Wala

32

Good morning girls!

GOOD MORNING GIRL

33

$\begin{array}{lllll}\text { If } & \text { you } & \text { move } & \text { to } & \text { tables } \\ \text { I-F } & \text { YOU } & \text { MOVE } & \text { TO } & \text { TABLE }\end{array}$

Ali

$\begin{array}{llcccc}\text { 34: } & \text { Today we } & \text { want to } & \text { learn } & \text { about colours } & \\ & \text { NOW } & \text { WANT } & \text { LEARN } & \text { ROUND COLOUR } \\ \text { 35 } & \text { Now these } & \text { colours } & \text { are divided } & \text { into groups }\end{array}$

\section{INDEX + left DIVIDE}

\section{GROUP}

The four sentences, which show omission of plural marker, have been used to show how sentences meaning can be lost through omission of number marker. 


\subsection{Semantic analysis}

Because researchers eg. Maxwell \&Bernastein (1985) have claimed that lack of a one-to one speech -to sign in SC may not necessarily affect message transfer from spoken to sign channels, this study further included the semantic dimension, thus analyzing the transcriptions at the discourse level. The study analysed the semantic properties of words and morphemes and the subsequent role that each word played in the phrase or the sentence. The objective here was to assess the degree to which the sign message and speech message corresponded at the level of meaning. Semantic Intact Ration (Stahlman\&Luckner, 1991), taxonomy for coding bimodal communication was used. In the analysis, the number of semantically intact utterances were counted and divided by the total number of utterances in the whole sample. The resultant ratio was then multiplied by 100 to express the result as a percentage as reflected here below:

$$
\underline{\text { SIUx } 100=M R}
$$

TNL

Where SUI represented the number of Semantically Intact Utterances, TNIL represented that Total Number of Utterances in language sample, and MR represented the Meaning Ratio expressed as a percentage. Using the coding procedure, meaning ration was calculated for each of the transcripts as shown in the following example.

The cows walked down the valley QUANTITY+TIME+LA

\section{COW COWCOW WALK past marker DOWN VALLEY}

$$
\text { QUANTITY+TIME+LA }
$$

Semantic codes for spoken and signed comments appear case $\mathrm{n}$ the right hand side, where in the forgoing example, QUANTITY represents the number of (cows), TIME represents the past tense (walked) and LOCATION ACTION stands for the place (down the valley. The utterance shows that both sentences, signed and spoken have the same number of semantic codes as is reflected on the right hand side. In the following sentence however,

$\begin{array}{rccc}\text { My rotten bananas are here } & \text { POSSESSION }+ \text { STATE }+ \text { QUANTITY }+L S \\ \text { BANANA } & \text { HERE } & \text { QUANTITI+LS }\end{array}$

Obligatory sign my (POSESSION) and rotten (STATE) encoded in speech are not signed. The resultant signed message is different from originally intended message. The meaning ration here calculated using semantic codes is computed as follows:

$$
\begin{gathered}
\text { SUI X } 100=M R \\
\text { TNIL } \\
\underline{2 \times 100}
\end{gathered}
$$

4

M.R. Ration $=50 \%$

For the present study, utterances filmed for 20 minutes for teachers were analyzed for meaning equivalence. Semantic codes explained in the forgoing were used to determine how much meaning was transferred from spoken to signed utterances. Sample of the extracted analyzed utterances are given 3637.

Wala 36: Now Today we want to learn about one table

\section{TODAY WE WANT TO LEARN ABOUT ONE TABLE}


$\underline{T I M E+Q U A N T I T Y+A C T I O N+N O T I C E+Q U A+A T T R I}$

TIME + QUANTITY + ACTION + NOTICE + QUA+ATTRI

Ali 37: Last time we drew a man standing

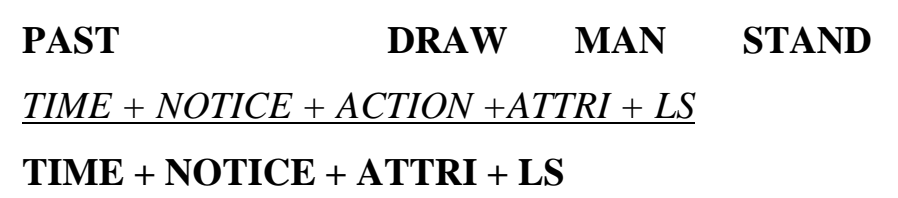

In the sentences above (Ali 36 and Ali 37), the same numbers of semantic codes are represented in both spoken and sign utterances. The same meanings are encoded in both the signed and spoken utterance. However in Ala 38, some semantic codes preset in spoken utterances, for instance, ACTION, LOCATION (L) LOCATION ACTION (LA) encoded in speech are not signed. The spoken and signed utterances are not therefore meaningfully equivalent.

Wala 38: Clicktools on your computer

YOU COMPUTER

NOTICE + ACTION + L + LA + POSSESION + Q

ENTRY + NOTICE + QUANTITY

Other examples of utterances, which lacked semantic equivalence between the spoken and signed utterances, were:

Ali 39:

$\begin{array}{lcc}\text { Who } \text { is } \quad \text { not } \text { in } & \text { today? } \\ \text { WHO } & & \text { TODAY+ QF } \\ \text { NOTICE }+L A+D E N I A L+\text { TIME + QUANTITY } & \end{array}$

NOTICE + TIME

Ala 40

$\begin{aligned} & \text { This one has said we have white colours } \\ & \text { WHITE }\end{aligned}$
INDEX+LEFT
SPEC + TIME + ACTION + POSSE + ATRI + QUANTITY
SPECIFIER + ATTRI

1. Ali generated 870 spoken free morphemes, yielding a corpus of 148 spoken spontaneous sentential utterances. Both spoken and signed utterances were analyzed for semantic intact ratio using semantic codes as explained in the foregoing. Results revealed that out of the 148 utterances, only 51 spoken utterances were semantically intact with sign . Semantic Intact Ratio was computed as follows:

$\begin{array}{rll}\text { Total number of spoken utterances } & = & 148 \\ \text { Semantically intact utterances } & = & 51 \\ \text { Semantic ratio expressed as percentage } & = & \underline{51 \times 100}\end{array}$ 
2. Ala generated a total of 760 free morphemes. This yielded a corpus of 119 spoken sentential utterances. Analysis for meaning ratio revealed that only 29 sentences were semantically intact with sign. Semantic intact ration was therefore computed as follows:

$$
\begin{aligned}
\text { Total number of spoken utterances } & =119 \\
\text { Semantically intact utterances } & =29 \\
\text { Semantic ratio expressed as percentage } & =\underline{29 \times 100}
\end{aligned}
$$

$$
\text { S.I.R }=24 \%
$$

3. Wala produced 915 spoken free morphemes yielding a corpus of 120 spoken sentential utterances, 76 of which were synchronized and were semantically intact with sign. Meaning ratio expressed as percentage was computed as follows:

$$
\begin{array}{ll}
\text { Total number of spoken utterances } & =120 \\
\text { Semantically intact utterances } & =76 \\
\text { Semantic ratio expressed as percentage } & =\underline{76 \times 100}
\end{array}
$$

$$
\text { S.I.R }=63 \%
$$

\subsection{Discussion}

Based on the forgoing SC analyses at both morphological and semantic levels, we noted that there were major findings in the investigation. First, the sign-to-voice and the semantic intact ratio calculated for teachers through SC showed large omissions of obligatory signs, and sign-word mismatch, which rendered SC transmission confusing, and to a large extent meaningless. Analysis of the teacher's SC transcriptions revealed difficulty on the part of the teachers to maintain simultaneity. Thinking in terms of Bellugi and Fischer (1972) assertion that the rate of articulation for speech alone is twice the rate of sign alone, the teachers apparently tried to resolve the difference in an attempt to maintain simultaneity. This difficulty apparently gave rise to deletions within the signed channels resulting in incomplete and meaningless utterances, yet it is meaning that facilitates comprehension (Bower et al 1975). In these circumstances therefore, pupils may have difficulties to deduce meaning from the resultant signed utterance with gaps.

It was clear that there was evidence of failure to reach Luetke Stahlman's recommendation of sign-tovoice ration and semantic intact ratio of $90 \%$. Noted were largeo mission of obligatory signs. Together with these were mismatch of speech and sign, which lead the communication into confusion, as the utterances remained unintelligible. Meaning was largely affected in a large percentage of the teachers' presentations. This finding is crucial to the present study as it has negative implication for SC as an instructional tool, especially if it is considered in the light of the information processing perspective which postulates that meaning enhances comprehension and memory recall.

The requirement of continuously thinking about what to say and how to encode the thought in different channels while simultaneously expressing those thoughts in two channels is also a factor influencing large omissions of signs. This was established in a study, Mamor \& Patitto (1979) in which the teachers who had many omissions in the spontaneous communication were asked to speak and sign the written information and did much better in the synchronization of speech and sign. It appears that although hearing teachers may be able to learn to use SC with some degree of accuracy, the requirement of having to use it during spontaneous speech such as in teaching situation may result into a cognitive overload that may yield a high presence of sign omissions. It should however be noted that the findings reported in this study for the semantic intact ratio contradicts those reported by Maxwell, Bornstein \& Mathews (1990) 
whose results showed semantics/message match between speech and sign and whose propositional or semantic content of the languages were the same.

The discrepancy in delivery during SC transmission seems to lead to the main problem in communicating a complete message in the signed medium as compared to the spoken medium. Hearing speakers may have the false sense that they are signing all the words that they are speaking while they don't. The role of any mode of communication is to encode a message in the mode of delivery, which in turn is decoded by the receiver. As Vasishta and Kendrick (2002) note;

If encoding is insufficient or defective, the decoding process will only provide misinformation, thus, nullifying the purpose of communication (p.182).

Mismatches as a result of speech-sign contradictions were reasonably detected in two teacher's utterances. Ali and Wala had very few contradictions. All the transcriptions did not show evidence of tense marking as required by the principles of SC. However a few utterance were marked in the past using sign language strategies. Number markings on nouns was noticeably lacking in all the transcripts.

Looking at the spoken channels of all the three transcriptions, it was evident that the teachers restricted themselves to what they wanted to say to avoid difficulties of translating what they say in sign. The speech components of the SC were simpler and less varied especially for Wala and Ali. Both offered less enriched language and less academic stimulus with a lot of grammatical mistakes, all the times repeating the same phrases to communicate the different ideas. In this way, it was not only the full subject content that $\mathrm{SC}$ could fail to deliver but also fail to facilitate the acquisition of English grammar.

Generally the analysis for the whole study on semantic equivalence revealed varied results for the teachers. Perhaps with more training and rigorous practice, the results could be different. However, the results of the present study are a paradox especially if it is borne in a mind that they were selected by their colleagues and the administration due to their superior command of SC. The performance is surprisingly low as the underlying principle of SC is the simultaneous presentation of sign and speech.

This discussion is not a condemnation of the efforts of those who have attempted to develop the systems representing spoken languages. Their efforts are highly appreciated as they have gone a long way to promote manual communication in deaf education in Kenya. It is an attempt to consider the representational systems in the light of their actual use. Since these systems have failed to meet their original goals, a better way of communication should be identified and such finding should be based on the findings that research on KSL and SC has provided.

\subsection{Conclusion}

Problems with SC have been identified and the study has demonstrated why SC may not be an appropriate communication mode or language of instruction in classes for the deaf learners. However it should be mentioned that there is a role for signed spoken language separate from signing and speaking at the same time. Its use will assist deaf children as they struggle to understand the difference between KSL, English syntax, morphology, reading and writing.

\section{References}

1. Adoyo P.O. (2004).Kenyan Sign Language and Simultaneous Communication.Differential effects on Memory and Comprehension in Deaf Children in Kenya. Lake publishers, Kisumu, Kenya

2. Akamstsu, T.C. \& Steward, A.D. (1998).Constructing Simultaneous Communication: The Contribution of National Sign Languages.Journal of Deaf Studies and Education, Oxford University Press. Volume 3, No. 4: 302-319.

3. BEllegi, U, R Fisher S, (1972). A comparison of Sign Language and Spoken Language.Cognition. 
4. Bloom, L., \&Lahey, M. (1978), Language Development and Language Disorders. New York: Wiley

5. Johnson et.al (1989).Unlocking the curriculum.Principles for Achieving Access in Deaf Education.Working paper, Washington DC.Grallaudet Research Institute.

6. Lane, H., Hoffmeister, R., and Bahan, B., (1996). A journey into the Deaf world Dawn Sign Press, San Diego, California.

7. Mammor, S. \&Pattito L. (1979). Simultaneous Communication in the Classroom. How well is English Grammar Represented? Sin language Studies, Linstock Press 23.99-136.

8. Maxwell, M.M. \& Bernstein, K. (1985). The Synergy of Sign and Speech is Simultaneous Communication. Applied Psycholinguistics, 6 (169:63-81).

9. Maxwell, M. Berstein, M. Mathews, K. (1990).Bimodal Language Production. In: P: Siple\& S. Fischer (eds), Theoretical Issues in Sign Language Research Chicago, II: University of Chicago Press: Vol. 2: 171190.

10. Visishta, M.M. \& Kendrick, H. (2001). Other Modes of Communication: In J.F. King Introduction to Deaf Education. A Deaf perspective: Buttle Publication, Inc, 1775-183 